\title{
ETFs versus CEFs: Performance in International Equity Investing
}

\author{
C. Edward Chang ${ }^{1}$, Kent P. Ragan ${ }^{1} \&$ H. Doug Witte ${ }^{1}$ \\ ${ }^{1}$ College of Business, Missouri State University, United States \\ Correspondence: C. Edward Chang, College of Business, Missouri State University, Springfield, MO 65897, \\ USA. Tel: 1-417-836-5563. E-mail: EdwardChang@MissouriState.edu
}

Received: September 11, 2013

Accepted: October 10, $2013 \quad$ Online Published: November 26, 2013

doi:10.5539/ijef.v5n12p79

URL: http://dx.doi.org/10.5539/ijef.v5n12p79

\begin{abstract}
Exchange-traded funds have experienced rapid growth in the last twenty years. We compare the performance of these funds to competing closed-end funds in the international equity investment setting. Expense ratios, turnover, risk, and return are examined over a ten year period ending in 2012. The expenses and turnover rates for exchange traded funds were significantly lower. However, closed-end fund returns after deducting expenses were significantly higher both unconditionally as well as on a risk-adjusted basis. Our findings suggest that unless the tax consequences of higher turnover are extreme, investors should forego the much hyped-lower expenses of exchange-traded funds and focus on the higher returns produced by closed-end funds.
\end{abstract}

Keywords: exchange-traded funds, closed-end funds, international investing, expense ratios, annual turnover, beta, risk-adjusted returns

\section{Introduction}

\subsection{Exchange-Traded Funds versus Closed-End Funds}

Introduced in the early 1990s, exchange-traded funds (ETFs) have become significant investment vehicles and today there exist more than 1,500 ETFs trading on U.S. exchanges. ETF assets under management in the U.S. have grown to nearly one trillion dollars. The merits of these funds are being increasingly extolled. Kennedy (2012) contends that one attractive feature of ETFs is that they make investing in foreign markets and countries easy. But are ETFs even a good way to invest internationally? Given that many closed-end funds offer a similar investment focus and can be viewed as substitutes for ETFs, a comparison of these funds is motivated. We compare the operational characteristics and investment performance of international equity ETFs relative to category-matched closed-end funds (CEFs).

ETF investments include stocks, bonds, commodities, and other assets. Similar to investment in a mutual fund, investors' gains or losses will be commensurate to the performance of the portfolio of assets in which the ETF has invested. These funds offer great liquidity because they trade throughout the day on a stock exchange. Additionally, ETFs typically trade at a price very close to their net asset values (NAVs) given their unique structure in which shares can be created or redeemed at any time with delivery of baskets of in-kind underlying securities. This means that material divergence between an ETF's share price and NAV is likely to be arbitraged away.

Similarly, CEF shares are bought and sold in a secondary market. However, the number of shares a particular CEF has outstanding remains constant over time because when a CEF is created it is very much like an initial public offering with no additional capital subsequently raised. Thus, all purchases and sales of CEF shares must be conducted with another investor in a secondary market transaction. In contrast, a traditional open-end mutual fund either creates new shares when new cash comes in or retires shares when disbursing cash.

ETFs are typically managed to mimic the returns of an index. In contrast, CEFs are actively managed in an attempt to beat the performance of an index benchmark. CEFs will therefore typically have higher expenses and higher turnover. Most ETFs, given their desire to track an index, have greater transparency regarding the composition of the underlying portfolio. Naturally, CEF managers in trying to beat index returns and charge a higher fee for their expertise, will minimize disclosure of their current portfolio composition. The greater transparency of ETF portfolios and the possibility of arbitrage cause ETF share prices to track more closely the net asset value of the underlying portfolio. In contrast, CEF share price and NAV can differ dramatically due to investor sentiment and impediments to arbitrage associated with these funds (see Lee, Shleifer, \& Thaler, 1990). 


\subsection{Literature Review}

Gastineau $(2001 ; 2002)$ chronicles the history of ETFs and the structure of these financial securities. Charupat and Miu (2013) offer an excellent summary of the ETF literature to date. Because ETFs do not have to sell shares in order to meet investor redemptions, capital gains taxes can be better managed (Madlem \& Edwards, 2002; Wiandt \& McClatchy, 2002). Buetow and Henderson (2012) find that ETFs exhibit little tracking error with respect to their benchmark indexes, especially when the benchmark is comprised of highly liquid securities. Although CEFs have been examined extensively (Zweig, 1973; Anderson, 1986; Lee, Shleifer, \& Thaler, 1990; Pontiff, 1997), most of the literature has focused on the apparent anomaly that CEFs often trade at a substantial discount to their NAV. Interestingly, Barnhart and Rosenstein (2010) find that CEF discounts widen considerably and trading volume drops significantly when a similar ETF is introduced. This finding suggests ETFs and CEFs are substitutes and further motivates a detailed comparison of the two investment vehicles.

Few papers have actually compared the performance of international equity ETFs and closed-end funds. This paper fills that gap. Articles related to ours include Harper, Madura and Schnusenberg (2006). They find that CEFs have lower returns and lower Sharpe ratios relative to comparable exchange-traded funds. Additionally, the closed-end funds in their sample had negative Jensen's alphas. However, the end of their sample predates the beginning of ours and so our results update the recent performance of ETFs and CEFs. Chang and Swales (2005) examine closed-end country funds and country-specific exchange traded funds using data from 11 countries. They find that ETFs had the advantage in terms of expenses and fund turnover but CEFs had better returns and less risk. Chang and Krueger (2012) confirm that country-specific ETFs low average market returns and inferior risk-adjusted returns. Our paper reports the performance of comparable international equity ETFs and CEFs in the most recent ten-year period ending in 2012. This era is of particular interest in light of the recent volatility in growth experienced by economies around the world. The global economy has grown by as much as $5 \%$ per year in recent years, but the expansion has had significant interruptions such as in 2009 in which a $2 \%$ contraction occurred.

\section{Comparative Fund Performance}

\subsection{Data}

We form our sample using all international equity ETFs and CEFs that have ten years of data. This affords us the opportunity to analyze longer-term fund performance from January 2003 thru December 2012. Additionally, recent performance tends to more influential to investors' decisions. For consistency, we obtain international equity ETF and CEF data from the same source, Morningstar's Principia website.

Table 1. Numbers of exchange-traded funds and closed-end funds for international equity investing with at least 10 years of data as of December 31, 2012

\begin{tabular}{lcc}
\hline \multicolumn{1}{c}{ Morningstar Category } & Exchange-Traded Funds & Closed-End Funds \\
\hline China Region & 2 & 3 \\
Diversified Emerging Markets & 1 & 3 \\
Diversified Pacific/Asia & 1 & 1 \\
Europe Stock & 15 & 7 \\
Foreign Large Blend & 2 & \\
Foreign Large Value & 1 & 1 \\
Foreign Small/Mid Value & & 2 \\
Japan Stock & 2 & 5 \\
Latin America Stock & 3 & 11 \\
Pacific/Asia ex-Japan Stock & 5 & 1 \\
World Stock & 2 & 34 \\
Total funds of available categories & 34 & 33 \\
Total funds of matched categories & 31 & \\
\hline
\end{tabular}

Note: For meaningful comparison, only category-matched funds are used for analysis.

Table 1 reports there are 34 ETFs in 10 Morningstar categories and 34 CEFs in 9 Morningstar categories from 
2003 to 2012. For meaningful comparison, only ETFs and CEFs in the same category were used for analysis. As a result, this study uses 31 ETFs and 33 CEFs in the same 8 categories. In the smallest category of Diversified Pacific/Asia, data is available for one ETF and one CEF only. In the largest category of Europe Stock, there are 15 ETFs and 7 CEFs. In order to give equal weight to each of the fund categories, we use the average value of share turnover, for example, for all funds within each category. These averages are used in the aggregate comparison of ETFs and CEFs performance, tests of differences in means, and reporting of statistical significance.

\subsection{Expense Ratios}

Mutual funds charge investors an annual fee for operating the funds. This fee, known as the expense ratio, is a percentage of fund assets charged each year to cover fund expenses including $12 \mathrm{~b}-1$ fees, management fees, administrative fees, operating costs, and all other costs incurred by the fund.

Table 2 shows that ETFs and CEFs have remarkably different expense ratios. The average CEF expense ratio is at least twice as large as the average ETF expense ratio in every category. Category averages for ETF expense ratios range from 37 to 67 basis points with an overall average of 55 basis points. In contrast, CEFs charged investors from 129 to 169 basis points for expenses, with the average being 152 basis points. The 97 basis point difference in overall average expense ratio is statistically significant at the one percent level. The higher expenses associated with CEFs is to be expected since these funds are actively managed whereas ETFs typically attempt to mimic an index benchmark.

Table 2. Expense ratio (\%), annual turnover (\%), and 10-year average annual return (\%)

\begin{tabular}{lcccccc}
\hline & \multicolumn{2}{c}{ Expense Ratio } & \multicolumn{2}{c}{ Annual Turnover } & \multicolumn{2}{c}{$\begin{array}{c}\text { Average } \\
\text { Annual Return }\end{array}$} \\
\cline { 2 - 7 } \multicolumn{1}{c}{ Morningstar Category } & ETFs & CEFs & ETFs & CEFs & ETFs & CEFs \\
\hline China Region & 0.67 & 1.69 & 19 & 65 & 10.43 & 17.44 \\
Diversified Emerging Markets & 0.61 & 1.52 & 29 & 37 & 15.20 & 19.11 \\
Diversified Pacific/Asia & 0.37 & 1.29 & 6 & 100 & 7.64 & 12.30 \\
Europe Stock & 0.52 & 1.54 & 14 & 35 & 8.38 & 12.41 \\
Japan Stock & 0.58 & 1.41 & 14 & 62 & 4.49 & 3.80 \\
Latin America Stock & 0.67 & 1.55 & 35 & 70 & 22.51 & 22.84 \\
Pacific/Asia ex-Japan Stock & 0.60 & 1.60 & 22 & 63 & 15.21 & 17.09 \\
World Stock & 0.40 & 1.59 & 14 & 111 & 4.87 & 13.62 \\
\hline \multicolumn{1}{c}{ Average of all categories } & 0.55 & 1.52 & 19.13 & 67.88 & 11.09 & 14.83 \\
\multicolumn{2}{c}{ T-test (probability) } & $0.000^{* * *}$ & \multicolumn{2}{c}{$0.002^{* * *}$} & $0.007^{* * *}$ \\
\hline
\end{tabular}

Note: ETFs: Exchange-traded Funds; CEFs: Closed-end Funds. ${ }^{* * *},{ }^{* *},{ }^{*}$ : Significant at the 0.01, 0.05, and 0.10 level.

\subsection{Annual Turnover}

The turnover rate or ratio is a measure of the fund's trading activity. Turnover ratio is computed taking the lesser of purchases or sales (excluding all securities with maturities of less than one year) and dividing by average monthly net assets. A lower turnover rate would be consistent with a buy-and-hold strategy whereas higher turnover is indicative of a more active investment strategy involving considerable buying and selling of securities.

The two middle columns of Table 2 report the turnover rates for the funds. ETF mean turnover is about 19 percent while CEF mean turnover is nearly 68 percent. This turnover rate difference is significant at the one percent level. The lowest CEFs have the same annual turnover (35\%) as the highest annual turnover among ETFs. These results are consistent with the more active management of CEF portfolios.

\subsection{Comparative Performance: Average Annual Returns}

Given the higher expenses and turnover of CEFs, the natural question is whether investors in these funds get what they pay for. We analyze annual average returns as measured by the investment funds' market returns, not 
the NAV return. The third pair of columns in Table 2 reports average annual returns for the funds in our sample. CEFs have a 3.74 percent higher average annual return (i.e., $14.83 \%-11.09 \%$ ) than do comparable ETFs and this difference is statistically significant at the one percent level. Furthermore, in seven of the eight categories, CEF average annual returns exceed those of ETF average annual returns. The lone exception is the Japan Stock category. Overall, our results suggest a big return advantage to CEFs over ETFs.

\subsection{Comparative Performance: Standard Deviations and Systematic Risk}

Obviously, most investors are concerned about return relative to risk. Standard deviation, a measure of the dispersion in returns around an average, indicates the variation in a fund's returns over a specified period of time. Investors often use the standard deviation of past returns to assess the possible range of returns going forward. The higher is the standard deviation of a fund's past returns, the wider is the range of possible future returns. In other words, the investor can expect greater volatility. Morningstar computes standard deviation from monthly total returns over a given time period and then annualizing this figure. The standard deviation pair of columns of Table 3 indicate that, on average, ETFs carried lower total risk than CEFs. The annualized difference is 1.94 percent and is statistically significant at the ten percent level.

Table 3. 10-year standard deviation (\%) and beta

\begin{tabular}{lcccc}
\hline \multirow{2}{*}{\multicolumn{1}{c}{ Morningstar Category }} & \multicolumn{2}{c}{ Standard Deviation } & \multicolumn{2}{c}{ Beta } \\
\cline { 2 - 5 } China Region & ETFs & CEFs & ETFs & CEFs \\
Diversified Emerging Markets & 23.44 & 24.09 & 0.94 & 0.97 \\
Diversified Pacific/Asia & 24.24 & 30.08 & 1.15 & 1.31 \\
Europe Stock & 19.79 & 19.14 & 0.97 & 0.95 \\
Japan Stock & 22.78 & 27.03 & 1.16 & 1.26 \\
Latin America Stock & 16.71 & 17.25 & 0.70 & 0.62 \\
Pacific/Asia ex-Japan Stock & 27.94 & 25.39 & 1.24 & 1.11 \\
World Stock & 23.03 & 25.52 & 1.04 & 1.07 \\
\hline \multicolumn{1}{c}{ Average of all categories } & 15.52 & 20.42 & 0.80 & 0.92 \\
\multicolumn{1}{c}{ T-test (probability) } & 21.68 & 23.62 & 1.00 & 1.03 \\
\hline
\end{tabular}

Note: ETFs: Exchange-traded Funds; CEFs: Closed-end Funds. ${ }^{* * *},{ }^{* *},{ }^{*}$ : Significant at the 0.01, 0.05, and 0.10 level.

In contrast to standard deviation which measures a fund's total risk, beta is a measure of a fund's sensitivity to market movements. Thus, beta measures only the portion of a fund's risk that is systematic and cannot be diversified away. Morningstar calculates beta using the correlation between a fund's excess return over Treasury bills and the market's excess return over Treasury bills. Table 3 reports that ETFs have an average beta of 1.00 and CEFs have a slightly higher average beta of 1.03. The p-value of .241 indicates that the difference is not statistically significant. The individual fund categories suggest material variation in betas and that CEFs had higher betas in five of the eight categories. Overall, it does not appear that ETFs have less systematic risk than CEFs. Consequently, differences in betas have little ability to explain the tremendous return advantage afforded by CEFs over ETFs we report above.

\subsection{Comparative Performance: Sharpe Ratios, Treynor Measures, and Jensen's Alphas}

We analyzed three risk-adjusted return measures in comparing international equity ETFs and CEFs. The Sharpe ratio divides a fund's excess return over a 90-day Treasury bill by the standard deviation of the fund's excess returns. The result is a measure of reward per unit of risk. The bigger is the Sharpe ratio, the more return an investor has achieved in relation to the risk undertaken. The Sharpe Ratio columns in Table 4 indicate that, on average, ETFs have a lower Sharpe ratio (0.48 vs. 0.59$)$ than CEFs, and the difference is statistically significant at the five percent level. 
Table 4. 10-year sharpe ratio, treynor measure (\%), and alpha (\%)

\begin{tabular}{lcccccc}
\hline \multirow{2}{*}{ Morningstar Category } & \multicolumn{2}{c}{ Sharpe Ratio } & \multicolumn{2}{c}{ Treynor Measure } & \multicolumn{2}{c}{ Alpha } \\
\cline { 2 - 7 } & ETFs & CEFs & ETFs & CEFs & ETFs & CEFs \\
\hline China Region & 0.48 & 0.68 & 9.31 & 14.88 & 3.52 & 8.45 \\
Diversified Emerging Markets & 0.64 & 0.67 & 11.82 & 12.70 & 6.50 & 9.81 \\
Diversified Pacific/Asia & 0.39 & 0.56 & 6.25 & 9.96 & 0.11 & 3.27 \\
Europe Stock & 0.39 & 0.48 & 5.62 & 7.65 & -0.36 & 3.13 \\
Japan Stock & 0.23 & 0.24 & 3.62 & 4.82 & -1.68 & -0.68 \\
Latin America Stock & 0.81 & 0.83 & 16.55 & 17.74 & 12.78 & 12.17 \\
Pacific/Asia ex-Japan Stock & 0.66 & 0.64 & 13.29 & 13.48 & 6.74 & 7.88 \\
World Stock & 0.27 & 0.65 & 3.79 & 12.92 & -2.16 & 5.96 \\
Average of all categories & 0.48 & 0.59 & 8.78 & 11.77 & 3.18 & 6.25 \\
$\quad$ T-test (probability) & \multicolumn{2}{c}{$0.027^{* *}$} & \multicolumn{2}{c}{$0.014 * *$} & $0.007^{* * *}$ \\
\hline
\end{tabular}

Note: ETFs: Exchange-traded Funds; CEFs: Closed-end Funds. ${ }^{* * *},{ }^{* *},{ }^{*}:$ Significant at the $0.01,0.05$, and 0.10 level.

The Treynor measure is similar to the Sharpe ratio in that it gives average excess return per unit of risk incurred, but the Treynor index uses systematic risk (beta) rather than total risk (standard deviation). The ETFs have an average Treynor measure of 8.78 percent, which is nearly 3 percent less than the 11.77 percent average of CEFs. This difference is significant at the five percent level. In all eight fund categories, CEFs have an average Treynor measure which exceeds that of comparable ETFs.

Jensen's alpha measures the amount of fund return that is independent of the fund's systematic risk as measured by beta. It is sometimes called "abnormal return" because if 1) markets are efficient, 2) funds are diversified, and 3 ) return is compensation for bearing only market risk, Jensen's alpha should be 0 . A positive (negative) alpha suggests the fund has delivered returns beyond (below) what was expected given the fund's beta and the Capital Asset Pricing Model (CAPM) of returns. Fund managers strive to deliver consistently positive alpha as it is indicative of superior stock-picking ability and/or superior ability to time the market. Investors seek out funds that can deliver positive alpha since it represents extra return that comes without having to take extra risk.

CEF alphas are 3.07 percent larger than those of ETFs and the difference is significant at the one percent level. In seven of eight categories, CEFs have average alpha larger than those of ETFs. The lone exception is the higher alpha of the Latin America Stock ETFs.

\subsection{Comparative Performance: Sortino Ratios and Downside Capture Ratios}

The Sortino ratio is similar to the Sharpe ratio in that it is a risk-adjusted measure of return, but rather than characterizing all volatility as risk, the Sortino ratio uses only downside deviation in assessing risk. The rationale is straightforward. Volatile returns to the upside benefit an investor whereas volatility from negative returns is harmful. The Sortino ratio is calculated by taking a fund's excess return over the risk-free rate and dividing by the downside semi-deviation. The denominator will most often be calculated using squared negative excess returns. Intuitively, the Sortino ratio is a measure of return relative to harmful volatility and provides the investor with a clearer assessment of the risk of a fund. The results in Table 5 indicate that ETFs have, on average, a lower Sortino ratio than CEFs ( 0.74 vs. 0.89 ), and the difference is statistically significant at the five percent level. 
Table 5. 10-year sortino ratio and downside capture ratio (\%)

\begin{tabular}{lcccc}
\hline \multirow{2}{*}{\multicolumn{1}{c}{ Morningstar Category }} & \multicolumn{2}{c}{ Sortino Ratio } & \multicolumn{2}{c}{ Downside Capture Ratio } \\
\cline { 2 - 5 } & ETFs & CEFs & ETFs & CEFs \\
\hline China Region & 0.73 & 1.02 & 113.45 & 82.20 \\
Diversified Emerging Markets & 0.98 & 1.03 & 117.38 & 114.71 \\
Diversified Pacific/Asia & 0.59 & 0.83 & 100.42 & 90.52 \\
Europe Stock & 0.56 & 0.68 & 121.11 & 120.03 \\
Japan Stock & 0.34 & 0.37 & 74.88 & 64.76 \\
Latin America Stock & 1.28 & 1.25 & 98.65 & 91.35 \\
Pacific/Asia ex-Japan Stock & 1.02 & 0.99 & 100.04 & 87.89 \\
World Stock & 0.38 & 0.96 & 92.78 & 74.81 \\
\hline \multicolumn{1}{c}{ Average of all categories } & 0.74 & 0.89 & 102.34 & 90.78 \\
\multicolumn{2}{c}{$0.036^{* *}$} & \multicolumn{2}{c}{$0.006^{* * *}$} \\
\hline
\end{tabular}

Note: ETFs: Exchange-traded Funds; CEFs: Closed-end Funds. ${ }^{* * *},{ }^{* *},{ }^{*}:$ Significant at the $0.01,0.05$, and 0.10 level.

Much like the Sortino ratio's focus on standard deviation below the mean, downside capture ratios have gained popularity because of their ability to provide important investment insights regarding risk that are easily understood by investors. Downside capture ratios compare a fund's performance to a benchmark during periods when the benchmark's performance is negative. A capture ratio greater than (less than) $100 \%$ indicates that a fund's return was worse (better) than the market return during declines. Thus, investors will fare better when a fund has a downside capture ratio less than $100 \%$. The results from Table 5 indicate that the ETFs had a downside capture ratio of 102.34 percent. In contrast, the CEFs had a downside capture ratio of 90.78 percent. The p-value of .006 suggests this difference is unlikely due to chance. Consistent with the Sortino ratio results, CEFs appear to soften market losses by 9.22 percent $(90.78 \%-100 \%)$ while ETFs magnified market losses by 2.34 percent $(102.34 \%-100 \%)$.

\section{Conclusion}

At this time, mutual funds account for about one-quarter of household financial assets. First created in the early 1990s, exchange-traded funds now number over 1,500 in the U.S. Closed-end funds have been in existence for over 100 years and there are around 600 of these funds operating in the U.S. Given their more recent introduction, ETFs have naturally been heavily promoted by investment companies. The financial press as well as television and print advertising frequently tout the merits of ETFs. The emphasis is usually place on the cheap costs of owning an ETF as well as the tremendous liquidity they offer. However, most investors are just as likely to consider returns after expenses and risk.

We compared the performance of international equity ETFs and CEFs from 2003 to 2012. We examine the international equity setting because of growing awareness that investing internationally may offer higher returns as well as portfolio diversification. Our sample contains funds for which ten years of data can be obtained, funds that have a Morningstar category, and funds with at least one ETF and one CEF in that category. As expected, we find that international equity ETFs have lower expense ratios. They also have lower annual turnover rates and lower standard deviations. International equity CEFs, on the other hand, had significantly higher after-expenses returns and similar risk. The CEFs had higher risk-adjusted returns as measured by the Sharpe ratio, the Treynor measure, and Jensen's alpha. Furthermore, CEF investors appear to benefit from lower downside risk. An obvious question for future research is the nature and source of CEFs' better return performance. Possibilities include better market timing and/or better security selection. The Sortino and downside capture ratio results we report are consistent with CEFs holding more cash during market downturns, to the benefit of their investors. Additionally, there is widespread belief that international financial markets are less efficient than U.S. markets and actively managed funds can earn abnormal returns. Our results are also consistent with this proposition.

Our conclusion is that investors should give CEFs another look. Although these funds have been around for more than 100 years and have faded from prominence, CEF investment over the last decade would have given an investor a much higher portfolio value today and a smoother ride along the way. An interesting question for future research is whether or not data from longer periods will validate our findings over this most recent era of 
ETF and CEF performance.

\section{References}

Anderson, S. A. (1986). Closed-end funds versus market efficiency. Journal of Portfolio Management, 13, 6365. http://dx.doi.org/10.3905/jpm.1986.409078

Barnhart, S. W., \& Rosenstein, S. (2010). Exchange-traded fund introductions and closed-end fund discounts and volume. Financial Review, 45, 973-994. http://dx.doi.org/10.1111/j.1540-6288.2010.00281.x

Buetow, G. W., \& Henderson, B. J. (2012). An empirical analysis of exchange-traded funds. Journal of Portfolio Management, 38, 112-127. http://dx.doi.org/10.3905/jpm.2012.38.4.112

Chang, C. E., \& Krueger, T. M. (2012). The case for country-specific closed-end funds instead of exchange-traded funds. International Business Research, 5(5), 3-7. http://dx.doi.org/10.5539/ibr.v5n5p3

Chang, C. E., \& Swales, G. S. Jr. (2005). A comparative study of risk and performance measures of closed-end country funds and country-specific exchange-traded funds. Journal of the Academy of Finance, 3, 109-116.

Charupat, N., \& Miu, P. (2013). Recent developments in exchange-traded fund literature. Managerial Finance, 35(5), 427-443. http://dx.doi.org/10.1108/03074351311313816

Gastineau, G. (2001). Exchange traded funds: an introduction. Journal of Portfolio Management, 27, 88-96. http://dx.doi.org/10.3905/jpm.2001.319804

Gastineau, G. (2002). The exchange-traded funds manual. New York: John Wiley.

Harper, J. T., Madura, J., \& Schnusenberg, O. (2006). Performance comparison between exchange-traded funds and closed-end country funds. Journal of International Financial Markets, Institutions and Money, 16, 104-122. http://dx.doi.org/10.1016/j.intfin.2004.12.006

Kennedy, M. (2012, February 17). 11 reasons for buying exchange-traded funds. Retrieved from http://etf.about.com/od/etfbasics/tp/Buying_ETFs.htm

Lee, C. M. C., Shleifer, A., \& Thaler, R. (1990). Anomalies: closed-end mutual funds. Journal of Economic Perspectives, 4, 153-164. http://dx.doi.org/10.1257/jep.4.4.153

Madlem, P. W., \& Edwards, L. D. (2002). Power investing with basket securities. New York: John Wiley.

Pontiff, J. (1997). Excess volatility and closed-end funds. American Economic Review, 87, 155-169. http://www.jstor.org/stable/2950859

Wiandt, J., \& McClatchy, W. (2002). Exchange traded funds. New York: John Wiley.

Zweig, M. E. (1973). An investor expectations stock price predictive model using closed-end fund premiums. Journal of Finance, 28, 67-78. http://dx.doi.org/10.2307/2978169

\section{Copyrights}

Copyright for this article is retained by the author(s), with first publication rights granted to the journal.

This is an open-access article distributed under the terms and conditions of the Creative Commons Attribution license (http://creativecommons.org/licenses/by/3.0/). 